\title{
ANÁLISE DOS EFEITOS ANTIMUTAGÊNICOS DE FRUTOS TROPICAIS EM ORGANISMO EUCARIOTOS
}

\section{MARILENE DA COSTA SANTOS}

\section{Centro de Ciências Biológicas e da Saúde, Pontifícia Universidade Católica do Paraná.}

Inúmeros componentes naturais da dieta humana apresentam efeitos antimutagênicos, como por exemplo, o alho que tem mostrado uma ação preventiva com relação ao câncer gastrointestinal, (Knasmuller e cols.,1989). Certos vegetais e frutas possuem atividade inibitória aos princípios mutagênicos dos produtos da pirrólise de proteínas e aminoácidos, (Kada e cols.,1978). Além disso, sucos vegetais mostram redução das aberrações cromossômicas induzidas "in vivo" pela 7,12dimetilbenzeno (Ito e cols., 1986). Na última década cerca de 100 testes rápidos "short-term" foram desenvolvidos com o objetivo de detectar substâncias com atividades mutagênicas, oncogênicas e/ou teratogênicas. Entre estes testes encontra-se o Teste de Ames, que baseia-se no uso de bactérias Salmonella typhimurium auxotróficas para o aminoácido histidina e que revertem a protrotofia pelo tratamento com agentes genotóxicos. O teste foi utilizado então para testar atividade antimutagênica, utilizando um agente mutagênico conhecido e suco de frutos tropicais, esperando que estes frutos impedissem a ação do agente mutagênico. Os frutos utilizados foram: acerola (Malpighia glabra L.), cajá (Spondias sp.), caju (Anacardium occidentale Linn.) e limão (Citrus sp.). Foram utilizadas as seguintes cepas de Salmonella typhimurium: TA100, que mede a presença de danos por substituição de pares de base e a TA102, que possui um par de base AT no sítio crítico para reversão, detectando uma variedade de substâncias oxidativas, formas ativas de oxigênio e agentes alquilantes. Estas cepas foram colocadas na presença de $10 \mu \mathrm{l}$ de cada suco e mais um composto mutagênico de efeito conhecido. A inibição da ação do composto mutagênico só ocorre quando o mutágeno é pré-incubado com o suco de frutas durante 30 minutos à $37^{\circ} \mathrm{C}$ antes de ser colocado em contato com a bactéria. 